\title{
Design and manufacturing of double sided automatic chamfering machine
}

\author{
Piyush Kumar", Akash M. Potdukhe Mahesh V. Bitode and Amit B. Belvekar
}

School of Mechanical And Civil Engineering, MITAOE, SPPU, Pune, India

Received 15 March 2019, Accepted 17 May 2019, Available online 20 May 2019, Vol.9, No.3 (May/June 2019)

\begin{abstract}
In this era of automation where it is broadly defined as replacement of manual effort by mechanical power in all applications of manufacturing. Chamfering is one of the major operation in manufacturing of automotive parts. Many small scale manufacturing industries performs this operation manually as per the requirement of customer. There are many industrial applications where round bar or square bars are required to be chamfered on different machines to make automotive components. To produce such mass productions manually consumes more time as well as man power. In this paper we have designed and developed automated double sided chamfering machine.
\end{abstract}

Keywords: Cam and Follower, Pulley, Automation, Chamfering

\section{Introduction}

This is an era of automation where it is broadly defined as replacement of manual effort by mechanical power in all degrees of automation. The operation remains an essential part of the system although with changing demands on physical input as the degree of mechanization is increased.

In present condition many non-automatic operated chamfering machines of different companies with different specifications are available for the use in shop floor. These machines are so precise that they can chamfer metal bars with minimum time made up of different materials but they have one and major disadvantage that those are not able for mass production. For industries to achieve the mass production, it is necessary to chamfer with high rate. So it is impossible to depend upon conventional chamfering machine and need the improvement in technology and design of such machines. This machine can automatic chamfer two sides simultaneously and to achieve mass production for maximum profit in related companies. As this machine overcomes all the limitations and drawbacks of conventional chamfering machines, it is also helpful for small scale industries due to its simple working and operating conditions along with its compatibility, efficiency and affordable price. A chamfer is a 45-degree bevelled edge that is built into various designs, including architectural and tech products. Chamfers also may be used in circuit board technologies where a 45-degree edge makes sense for a particular path.

*Corresponding author's ORCID ID: 0000-0002-3375-5050 DOI: https://doi.org/10.14741/ijcet/v.9.3.11
It can also chamfer various other materials, such as plastic, wood and steel etc. This paper proposes the prototype model of automatic chamfering machine which is able to chamfer simultaneously without any jerk and minimum vibrations. This prototype model overcomes the limitations of conventional chamfering machines which can chamfer single piece at a time. It is able to chamfer metal bars of different materials at same time and will be helpful in many industries due its compatibility, reliability and efficiency. In present condition many electrically operated chamfering machines of different companies with different specifications are available for the use in shop floor. These machines are so precious that they can chamfer metal bars with minimum time made up of different materials but they have one and major disadvantage that those are able to chamfer single piece of bar at a time. For industries to achieve the mass production, it is necessary to chamfer metal bars with high rate. So, it is impossible to depend upon conventional chamfering machines and need the improvement in technology and design of such machines.

\section{Design Approach}

The setup of our project consists of a bed on which the chamfering tools are mounted. The chamfering tool is mounted in the centre. The circular cam is mounted on the shaft at front level and operated by using motor. The power to the motor is given with the help of an AC supply. The cam mechanism is used to convert the rotary motion into the reciprocating motion. 


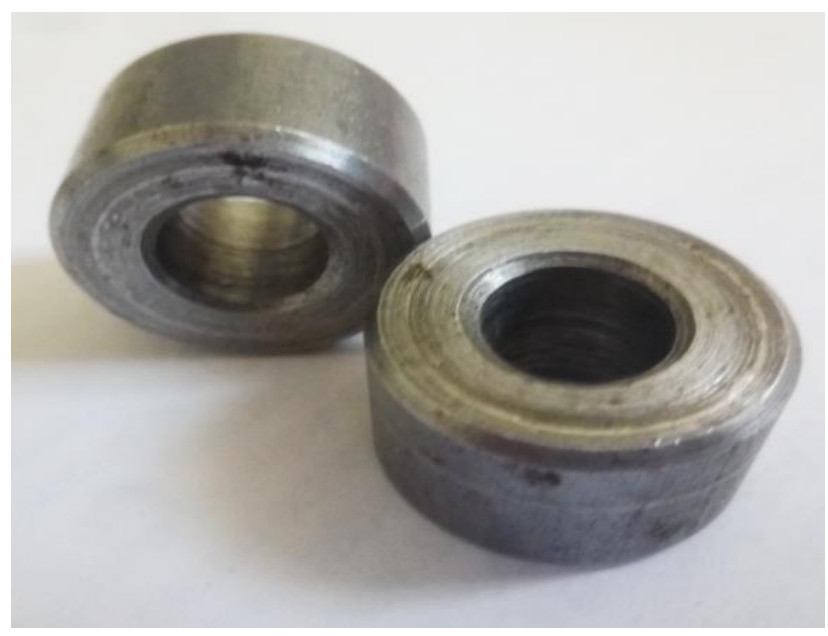

Fig. 1 Chamfered Parts

Hence when the motor is switched on, the power from the motor is delivered to the cam wheel. The cam wheel rotates such that the chamfered is done. The work pieces came from hopper mounted on top and due rotation of cam it came down. Thus the chamfering is done simultaneously by using the motor and the cam mechanism.

The above project mainly utilizes following main mechanisms:

- $\quad$ Bed

- AC Motor

- Cam and follower

- Chamfered tool

- Arm

- Shaft

- chuck

- Pulley

- Support

- $\quad$ Spring

\section{Bed}

This the part on which whole machine is mounted. Dimension is $1200 * 700 * 540$

\section{AC Motor}

An AC motor is an electric motor driven by an alternating current (AC). The AC motor commonly consists of two basic parts, an outside stationary stator having coils supplied with alternating current to produce a rotating magnetic field, and an inside rotor attached to the output shaft producing a second rotating magnetic field. The rotor magnetic field may be produced by permanent magnets, reluctance saliency, or DC or AC electrical windings.

\section{Cam and Follower}

CAM

A cam is a rotating or sliding piece in a mechanical linkage used especially in transforming rotary motion into linear motion.

\section{Follower}

It follows the cam rotation. And here in our project we have used roller follower.

\section{Middle Cam}

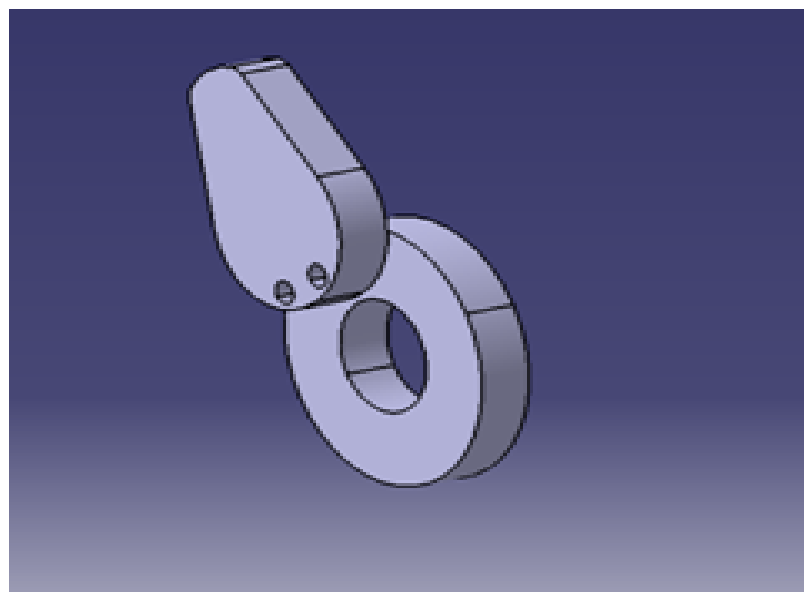

Fig. 2 Middle Cam with clamp

\section{Side Cam}

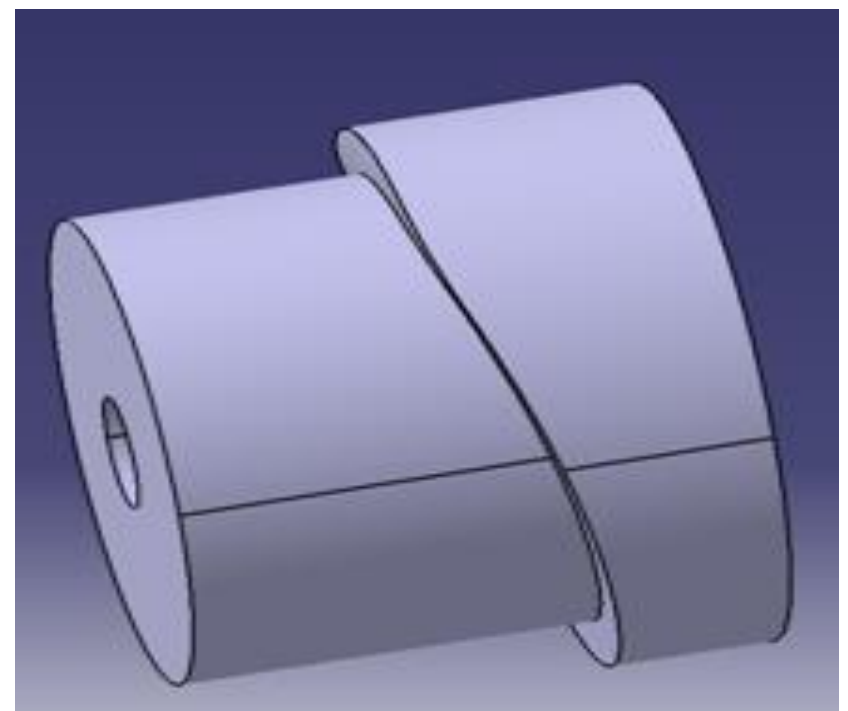

Fig. 3 Cylindrical side cam

\section{Chamfering Tool}

It is the tool which is used for chamfering. It is easy to use and which allows quick blade changes, making it a convenient solution for any manufacturing environment. Without any need to turn the work piece or to stop the spindle, it removes the burrs and chamfers the edges. 


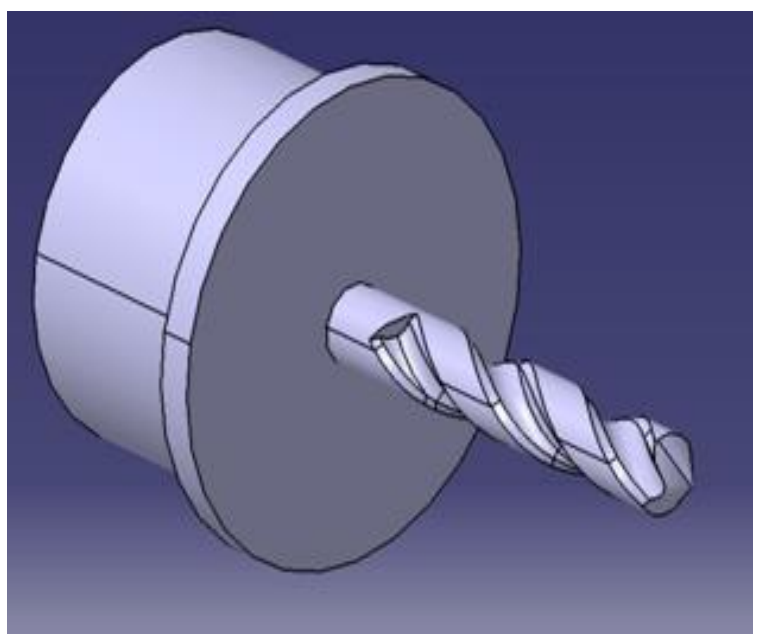

Fig. 4 Chamfering Tool

Arm

It is hinged to a point to move tool and job holding element.

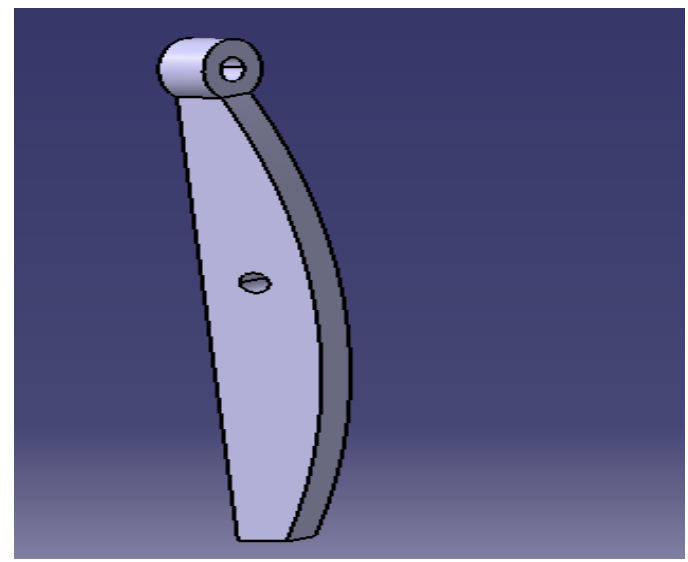

Fig. 5 Middle Arm

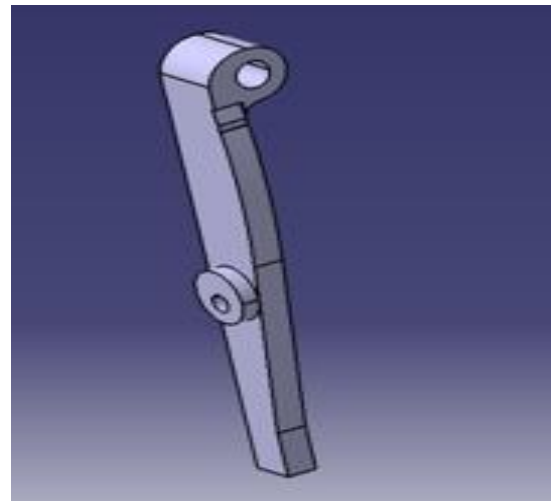

Fig. 6 Side Arm

\section{Shaft}

A shaft is a rotating machine element, usually circular in cross section, which is used to transmit power from one part to another, or from a machine which produces power to a machine which absorbs power. The various members such as pulleys and gears are mounted on it. And in our case cams are mounted on it.

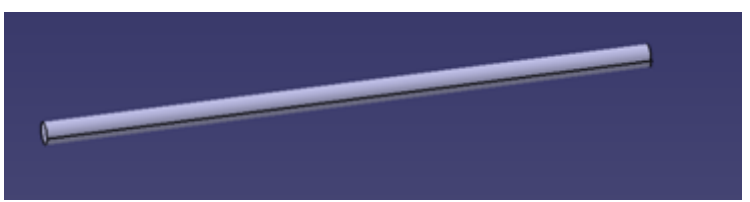

Fig. 7 Main Shaft

Chuck

A chuck is a specialized type of clamp used to hold an object with radial symmetry, especially a cylinder. In drills and mills it holds the rotating tool whereas in lathes it holds the rotating work piece. On a lathe the chuck is mounted on the spindle which rotates within the headstock.

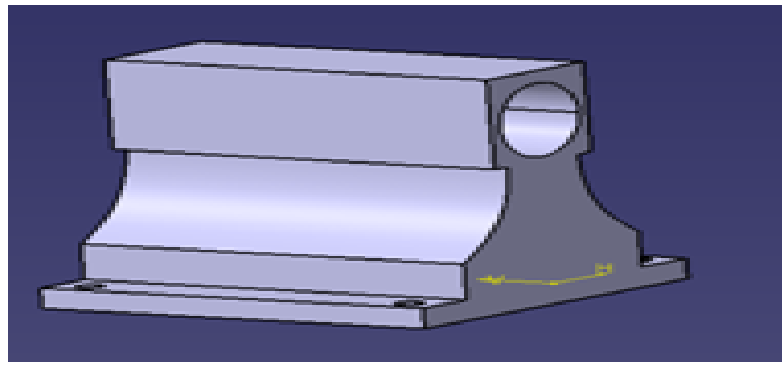

\section{Pulley}

Fig. 8 Chuck

A pulley is a wheel on an axle or shaft that is designed to support movement and change of direction of a taut cable or belt, or transfer of power between the shaft and cable or belt. In the case of a pulley supported by a frame or shell that does not transfer power to a shaft, but is used to guide the cable or exert a force, the supporting shell is called a block, and the pulley may be called a sheave.

A pulley may have a groove or grooves between flanges around its circumference to locate the cable or belt. The drive element of a pulley system can be a rope, cable, belt, or chain.

\section{Shaft Pulley}

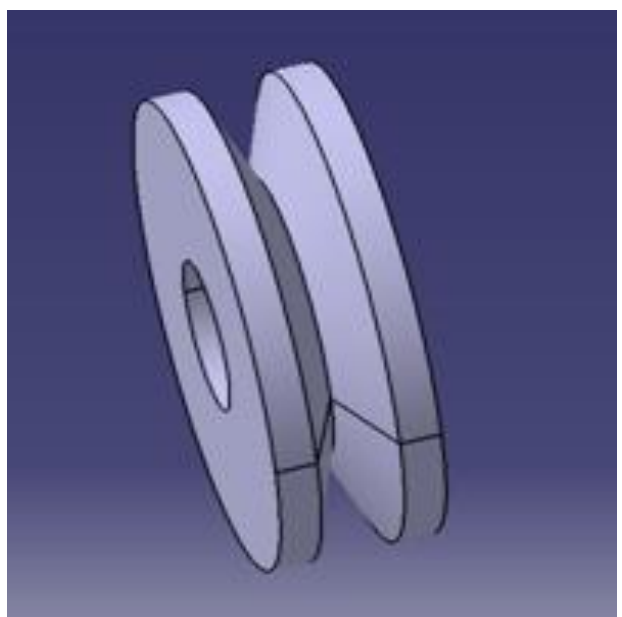

Fig. 9 Main shaft pulley 


\section{Support}

In our case it will help to support the job while cam operates.

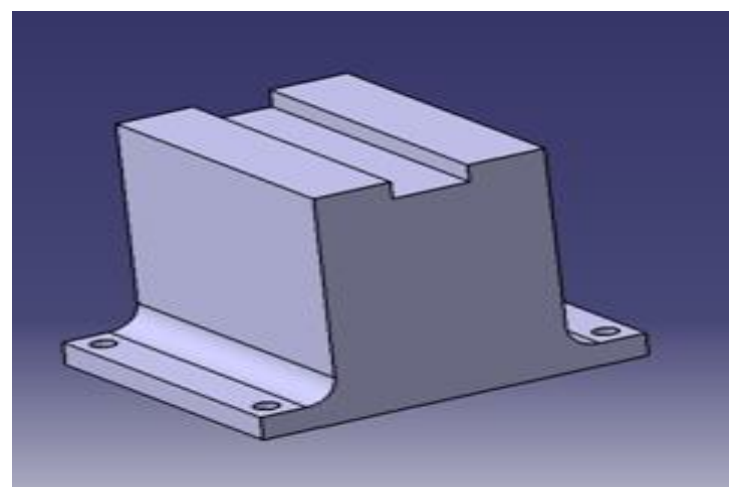

Fig. 10 Support no.1

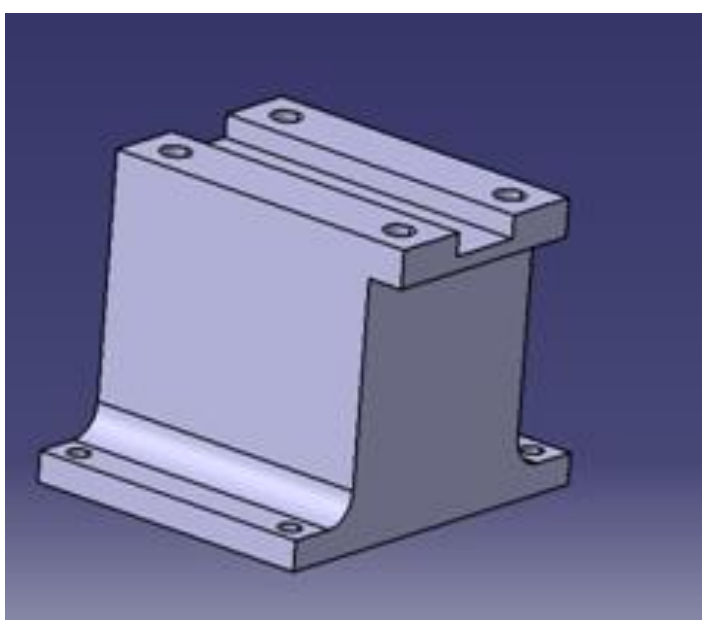

Fig.11 Support no. 2

\section{Spring}

A spring is an elastic object that stores mechanical energy. Springs are typically made of Spring Steel. There are many spring designs. In everyday use, the term often refers to coil springs. When a conventional spring, without stiffness variability features, is compressed or stretched from its resting position, it exerts an opposing force approximately proportional to its change in length. Springs are made from a variety of elastic materials, the most common being spring steel.

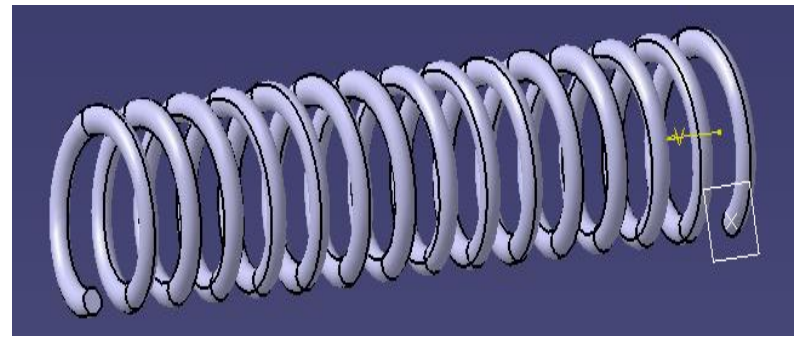

Fig. 12 Middle arm Bolt Spring

\section{Design Calculations}

Cam Design

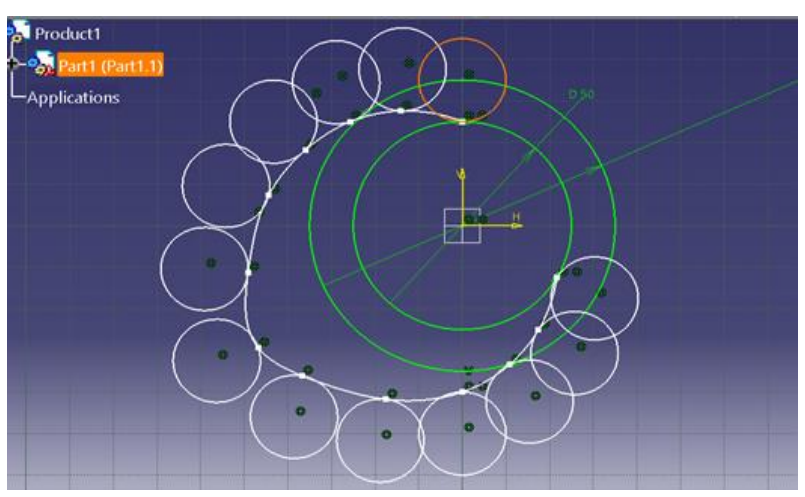

Fig.13 Cam Design

\section{Shaft Calculation}

Here, we have continuous support with three support two at end and one at middle

So, $\mathrm{M}=\mathrm{wL} \backslash 4=800 * 1300 \backslash 4$

$\mathrm{M}=26^{*} 10^{\wedge} 4 \mathrm{~N} \cdot \mathrm{mm}$

Suppose standard value of $\mathrm{Kb}=1.5 \quad \mathrm{Kt}=1$

$M_{e}=1 / 2\left[\left(k_{b} m\right)+\sqrt{\left(k_{b} m\right)^{2}+\left(k_{t} m\right)^{2}}\right]$

$\mathrm{P}=\frac{2 \pi N T}{60 * 1000}$

$\mathrm{T}=\mathrm{P} * 60 * 1000 / 2 \pi N$

$\mathrm{T}=152.52 * 10^{\wedge} 3 \mathrm{~N} . \mathrm{mm}$

Now,

$M_{e}=1 / 2$

$\left[\left(1.5 * 26 * 10^{\wedge} 4\right)+\right.$

$\left.\sqrt{\left(1.5 * 26 * 10^{\wedge} 4\right)^{2}+\left(1 * 152.52 * 10^{\wedge} 3\right)^{2}}\right]$

$=1 / 2\left[39^{*} 10^{\wedge} 4+\sqrt{\left(39 * 10^{\wedge} 4\right)^{2}+\left(152.52 * 10^{\wedge} 3\right)^{2}}\right]$

$=1 / 2\left[39^{*} 10^{\wedge} 4+\sqrt{1.52 * 10^{11}+2.32 * 10^{10}}\right]$

$=1 / 2\left[39^{*} 10^{\wedge} 4+\sqrt{1.753 * 10^{11}}\right]$

$M_{e}=4043.44^{*} 10^{2}$ N.mm

$6 \max =\frac{32 M_{e}}{\pi d^{2}} \ldots .$. Maximum Stress $6 \mathrm{max}=37 \mathrm{Mpa}$ (assume as per motor)

$37=\frac{32 * 4043.44 * 10^{2}}{\pi d^{3}}$

$T_{e}=\sqrt{\left(k_{b} M\right)^{2}+(k t . T)^{2}}$

$=\sqrt{\left(1.5 * 26 * 10^{\wedge} 4\right)^{2}+\left(1 * 152.52 * 10^{\wedge} 3\right)^{2}}$ 
$=\sqrt{1.52 * 10^{11}+2.32 * 10^{11}}$

$T_{e}=4186.88 * 10^{2} \mathrm{~N} \cdot \mathrm{mm}$

Allowable shear stress=23 Mpa (assume)

$\tau \max =\frac{16 T_{e}}{\pi d^{3}}$ $23=\frac{16 * 4186.88 * 10^{2}}{\pi d^{3}}$

$\mathrm{d}=45.25 \mathrm{~mm}$

Hence, above two value the select larger value [d =48mm]

Table 1 Material Strength

\begin{tabular}{|c|c|c|c|c|}
\hline Sr. No. & Part Name & Material & Tensile Strength (MPA) & Yield Strength (MPA) \\
\hline 1 & Bed & Grey Cast Iron & 150 & 415 \\
\hline 2 & Spindle & Steel Alloy & 655 & 310 \\
\hline 3 & Cam & Chilled Iron Casting & 450 & 310 \\
\hline 4 & Follower & Chilled Iron Casting & 450 & 415 \\
\hline 5 & Pulley & Steel Alloy & 655 & 225 \\
\hline 6 & Chamfering Tool & Cobalt (HSS) & & 80 \\
\hline 7 & Spring & Copper Alloy & 200 & 250 \\
\hline 8 & Shaft & Mild Steel & 370 & 215 \\
\hline 9 & Bearing & Stainless Steel & 505 & \\
\hline
\end{tabular}

\section{Assembled Machine}

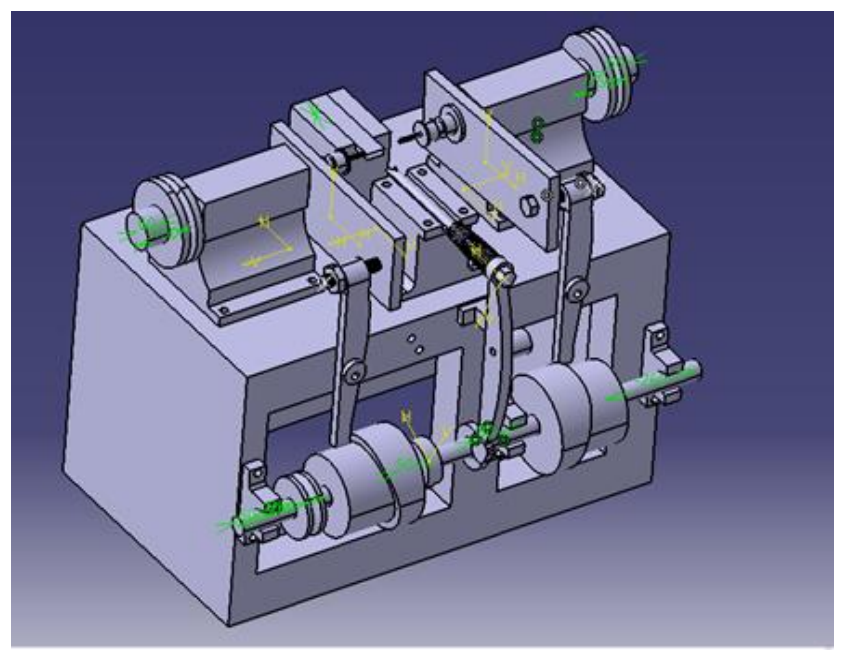

Fig.14 Assembled Machine

\section{Conclusions}

Conceptual design of Automatic chamfering machine is prepared in CATIA software. In addition, Cam and follower, Shaft, Pulley etc. are designed and calculated. Final machine layout is prepared in CATIA Software and assembly of the machine are presented in the paper.

\section{Future Scope}

1] The chamfering machine can be redesigned as per there requirements of an industrial component.

2] With the help of job feeding mechanisms, job carryout mechanisms \& different sensors, the machine can be effectively used in any kind of chamfering operation on all different sized jobs.

3] Automating the entire manufacturing line in the industry.

\section{References}

Nitinchandra R. Patel, Mohammad A. Vasanwala, Balkrushna B. Jani, Ravi Thakkar, Miteshkumar D. Rathwa, (June 2013)"Material selection and testing of chamfering based on mechanical properties", International Journal of Innovative Research in Science, Engineering and Technology, volume 2

O.Cakir, A. Yardimen, T. Ozben, (December 2007)“Selection of cutting fluids in machining processes", Journal of Achievements in Materials and Manufacturing Engineering, volume 25.

T. R. Jawanjal, S. T. Bagdem,( February 2013) 'An Advanced Chamfering System' International Journal of Emerging Technology and Advanced Engineering, Volume 3.

R.S.Khurmi, J.K.Guptal, (2012)"Theory of machines", Page no. 143-168

Sangram Kotkar, Dr. R. J. Patil, (June 2014)'Review on Chamfering Machine Operations', International Journal of Engineering Research \& Technology, Vol. 3. 